\title{
Selective Failure of Brain-Derived Neurotrophic Factor mRNA Expression in the Cerebellum of Stargazer, a Mutant Mouse with Ataxia
}

\author{
Xiaoxi Qiao, ${ }^{1}$ Franz Hefti, ${ }^{1}$ Beat Knusel, ${ }^{1}$ and Jeffrey L. Noebels ${ }^{2}$ \\ ${ }^{1}$ Andrus Gerontology Center, Univorsity of Southern California, Los Angeles, California 90089, and ${ }^{2}$ Department of \\ Neurology, Baylor College of Medicine, Houston, Texas 77030
}

In search of the possible involvement of neurotrophic factors in inherited neurological disease, we examined brain-derived neurotrophic factor (BDNF), nerve growth factor (NGF), and neurotrophin-3 (NT-3) mRNA expression patterns in the ataxic mutant mouse stargazer (stg). Using in situ hybridization, we found a selective and near total reduction in BDNF mRNA in the cerebellar granule cell layer. NT-3 or NGF mRNA expression in the cerebellum was normal. Northern blot analysis demonstrated a $70 \%$ reduction in BDNF mRNA in the whole cerebellum. BDNF mRNA levels in other mutant brain regions were unchanged. Absence of BDNF mRNA in granule cells was observed at postnatal age (P15), coincident with the onset of ataxia, and expression levels failed to follow the developmental increase found in the wild type at later ages (P20 and P30). Despite the severe BDNF reduction, in situ hybridization pat- terns for both the full-length and the truncated BDNF TrkB receptor mRNA were unaltered. No major cytoarchitectural abnormalities were apparent in the stg/stg cerebellum. BDNF expression in a related ataxic mutant, tottering, was unaltered. These data show that BDNF can be regulated selectively in distinct brain regions, possibly by differential activation of its multiple promoters. Absence of cerebellar granule cell BDNF mRNA in stg/stg mice demonstrates that sustained expression of this neurotrophin is not required for cell survival in the developing cerebellar cortex. Our data, in contrast, suggest a role of BDNF in maturation of specific cerebellar neurons and pathways. Early failure of cerebellar BDNF expression may be related to the ataxic phenotype in stg mice.

Key words: BDNF; NT-3; NGF; neurotrophic factors; TrkB receptor; differential gene expression; ataxia; cerebellum
Neurotrophic factors are key elements in the regulation of neuronal development and adult nervous system plasticity. Among them is the family of the neurotrophins that includes nerve growth factor (NGF), brain-derived neurotrophic factor (BDNF), and the neurotrophins 3 and 4/5 (NT-3, NT-4/5). BDNF is most abundant in the adult brain (Leibrock et al., 1989; Maisonpierre et al., 1990). Its mRNA is first detectable in the rat at embryonic day 11 (ED11) through ED12 and remains at a low level until late postnatal ages. In both the adult rat and mouse brain, the highest levels of BDNF transcripts are found in hippocampus, neocortex, and cerebellum (Hofer et al., 1990; Maisonpierre et al., 1990). In the cerebellum, BDNF mRNA is localized primarily in the granule cell layer (Hofer et al., 1990). In contrast to NT-3 mRNA expression, which peaks early during the first 2 weeks of postnatal development, BDNF mRNA in the cerebellar cortex of the rat peaks later, at approximately postnatal day 20 (P20) (Rocamora et al., 1993). The inverse temporal patterns of decreasing NT-3 mRNA and increasing BDNF mRNA expression coincide with granule cell migration and maturation.

Little is known about the effects of BDNF on cerebellar cells developing in vivo. Most of the results relating to the cellular

Received Aug. 31, 1995; accepted Oct. 20, 1995.

This work was supported by the following: National Institutes of Health Grants NS22933, AG09793, and AG10480; research grants from the National Parkinson Foundation, Miami, Florida (F.H.); NIH Grants NS29709, NS11535, and HD24064; and the Blue Bird Circle Foundation (J.L.N.).

Both B.K. and J.L.N. contributed equally to this study.

Correspondence should be addressed to Xiaoxi Qiao, Andrus Gerontology Center, 3715 McClintock Avenue, University of Southern California, Los Angeles, CA 90089-0191.

Copyright $\odot 1996$ Society for Neuroscience $\quad 0270-6474 / 96 / 160640-09 \$ 05.00 / 0$ actions of BDNF in this region are derived from the study of primary cultures of rat granule cells, in which BDNF has been found to enhance cell survival (Segal et al., 1992), to protect partially against neurotoxicity induced by high glutamate concentrations (Lindholm et al., 1993), and to promote maturation and neurite extension (Gao et al., 1995). Recent studies, using transgenic mice that lacked a functional BDNF gene, have found severe deficiencies in motor coordination and balance, head bobbing and tilting, circling behavior, and periods of immobility (Ernfors et al., 1994). Homozygous mutant mice were reduced in size compared with wild-type littermates, and most died during the second postnatal week. These behavioral abnormalities were associated with neuronal degeneration in vestibular and other sensory ganglia and with the failure of sensory axons to innervate target cells (Ernfors et al., 1994; Conover et al., 1995; I iu et al., 1995). Except for a slight delay in granule cell migration, no cellular abnormalities were detected in Nissl-stained sections of the cerebellum (Jones et al., 1994). However, because most mice did not survive beyond 2 weeks after birth, when cerebellar BDNF expression normally peaks, the potential trophic effects of BDNF on later stages of normal cerebellar maturation have not been determined fully.

The stargazer mouse (stg) is a recessive neurological mutation that arose spontaneously in the $\mathrm{A} / \mathrm{J}$-inbred strain at the Jackson Laboratory (Bar Harbor, ME). The locus was mapped by a series of linkage crosses to chromosome 15 between the $C a$ and $b t$ loci (Noebels et al., 1990). This mutant displays a unique phenotype consisting of ataxia, episodic upward tilting of the head in the vertical axis, and generalized spike-wave scizures accompanicd by behavioral immobility. Homozygous mutants can be recognized 
first at P14 by their ataxic gait. Spontaneous seizures characterized by neocortical spike-wave discharges $(6 / \mathrm{sec})$ are detected first at P18 and remain throughout the normal lifespan of the mouse (Qiao and Noebels, 1991, 1993). The product of the disrupted gene at the stg locus has not yet been defined.

In the present study, we characterized the developmental onset of ataxia in stg mutants and found severe defects of motor coordination and balance correlated with mild cerebellar hypoplasia. To test whether alterations in neurotrophic factors were involved in stg mice, we examined BDNF, NGF, and NT-3 mRNA expression patterns at different stages of development. We found an early and persistent regional failure of BDNF mRNA expression restricted to the stg cerebellum. Despite the striking reduction in BDNF, there were normal levels of mRNA for the other related neurotrophins and the BDNF receptor.

\section{MATERIALS AND METHODS}

Animals. Wild-type (C57BL/6J, $+/+)$ and mutant $\left(\mathrm{C} 3 \mathrm{~B} 6 \mathrm{Fe}^{+}\right.$, stg/stg) mice were obtained from breeding colonies of the Jackson Laboratory and maintained in the USC Gerontology Center vivarium on a $12 \mathrm{hr}$ on/12 hr off light/dark cycle with food and water available ad libitum. Heterozygous males $(+/ \mathrm{stg})$ and homozygous females $(\mathrm{stg} / \mathrm{stg})$ were mated to produce $s t g / s t g$ mutants (homozygous males are infertile; see Noebels et al., 1990). Mice of different ages, P15, P20, P30, and adult (2-4 months), were used in the experiments.

Behavioral tests. Motor coordination and balance for individual adult $+/+$ and $s t g / s t g$ mice ( $n=8 /$ group) were tested by inspection of their gait and righting response on a flat surface and by measuring their ability to balance on a stationary rod during a $60 \mathrm{sec}$ time trial (Ingram et al., 1981; McNeill et al., 1990). The plastic rod, $70 \mathrm{~cm}$ in length and $3 \mathrm{~cm}$ in diameter, was suspended between two safety platforms elevated to 12 inches. Soft foam-rubber bedding was placed under the rod to prevent injury in the case of a fall. During the test, the mouse was positioned in the middle of the balance rod and the amount of time it remained on the rod before falling was recorded up to a maximum of $60 \mathrm{sec}$. The mean latency on the rod for each mouse was obtained over six trials. A swimming test also was used to screen for deficits in vestibular behavior. A plastic tank $\left(12 \times 13\right.$ inch $\left.^{2}\right)$ filled with warm water was used for the swimming test. The mouse was placed in the center of the tank, and the righting response in water during a 2 min period was obtained over three trials. Mice unable to keep their head above water for $10 \mathrm{sec}$ failed the test, and longer times were scored commensurately (nominal scores: 0 , $<10 \mathrm{sec} ; 1,10-30 \mathrm{sec} ; 2,30-60 \mathrm{sec} ; 3,1-2 \mathrm{~min})$. The test was halted as soon as mice no longer were able to swim.

Histology. Two pairs of adult $+1+$ and stg/stg mice were perfused transcardially with $10 \%$ neutral formalin. The brains were removed from the skull, cut into $2-\mathrm{mm}$-thick sagittal slices, and post-fixed in the same solution for $24 \mathrm{hr}$ at $4^{\circ} \mathrm{C}$. Tissue blocks were embedded in paraffin. Sections were cut on a microtome at $6 \mu \mathrm{m}$ thickness and stained with Allen's hematoxylin and eosin (H-E).

In situ hybridization. cDNA clones of rat BDNF in a pGEM-4Z plasmid containing a 460 bp insert (Phillips et al., 1990), rat NT-3 in a pGEM-3Z vector with a 473 bp fragment (Phillips et al., 1990), and mouse NGF in pSP6FGN with a 900 bp insert (Scott et al., 1983) were obtained from Genentech (San Francisco, CA). Three types of $t r k \mathrm{~B}$ cDNA clones were used to distinguish the catalytic and noncatalytic receptors (Klein et al., 1989, 1990): (1) pFRK16 with a 483 bp insert encoding a portion of the extracellular domain of mouse TrkB receptor was used to generate pan probe to detect all forms of TrkB receptor (Klein et al., 1989); (2) pFRK29 containing a $280 \mathrm{bp}$ insert encoding the $\mathrm{C}$-terminal region of the catalytic domain was used to transcribe a $t r k \mathrm{~B} \mathrm{TK}^{+}$probe specific for tyrosine protein kinase receptor (Klein et al., 1990); and (3) pFRK31 with a $250 \mathrm{bp}$ insert encoding the noncatalytic receptors was used to synthesize a trkB TK-- probe (Klein et al., 1990).

${ }^{35} \mathrm{~S}$-labeled sense and antisense ribonucleotide probes were transcribed using Riboprobe Gemini System (Promega, Madison, WI). Mouse brains $(n=35)$ from both genotypes for each age were excised after decapitation and frozen on dry ice. Sections $(14 \mu \mathrm{m})$ were cut on a cryostat at

$-20^{\circ} \mathrm{C}$, mounted on subbed slides, and stored at $-70^{\circ} \mathrm{C}$. The mutant and wild-type brain sections of the same developmental ages were mounted together on the same slide and processed identically for optimal comparison. The sections were fixed with $4 \%$ p-formaldehyde in $0.1 \mathrm{M}$ PBS for 30

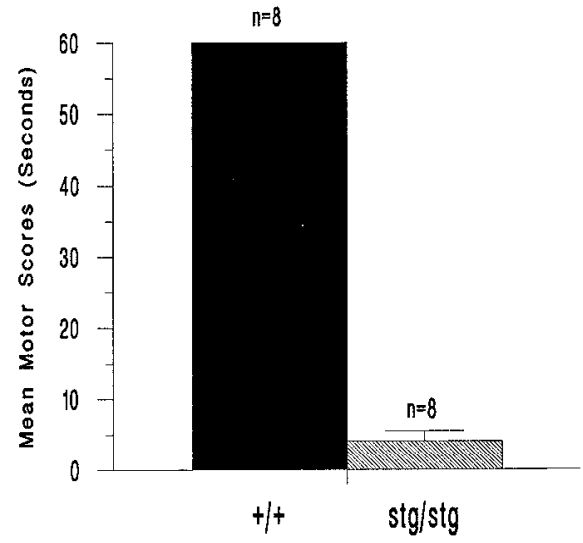

Figure 1. Motor and sensory deficits in stg/stg mice. Comparison of motor performance scorcs of adult $|/|$ control and stg/stg mutant micc $(n=8)$ on the stationary balance rod. All control mice remained on the rod for at least $60 \mathrm{sec}$, the cutoff time of the experiment. In contrast, all stg mice fell off the stationary rod after $<5 \mathrm{sec}$ [mean motor score $( \pm \mathrm{SEM}), 3.2 \pm 1.5$ sec; $p<0.01]$.

min, then pretreated with $0.25 \%$ acetic anhydrite and $0.1 \mathrm{M}$ triethanolamine for $10 \mathrm{~min}$. The tissue sections then were incubated overnight on a slide warmer at $50^{\circ} \mathrm{C}$ with the probe solution containing $5 \times 10^{6} \mathrm{cpm} / \mathrm{ml}$ ${ }^{35} \mathrm{~S}$-labeled riboprobe, $50 \%$ formamide, $10 \%$ dextran sulfate, $300 \mathrm{~mm}$ $\mathrm{NaCl}, 0.5 \mathrm{mg} / \mathrm{ml}$ yeast RNA, $10 \mu \mathrm{M}$ dithothreitol, $0.02 \%$ Ficoll, $0.02 \%$ polyvinyl pyrrolidone, $0.02 \%$ bovine serum albumin, and $1 \mathrm{mM}$ EDTA in $10 \mathrm{~mm}$ Tris- $\mathrm{HCl}, \mathrm{pH}$ 8.0. After hybridization, the slides were rinsed in $4 \times$ SSC (150 mM NaCl and $15 \mathrm{~mm} \mathrm{NaAc}$ ), digested with $20 \mu \mathrm{g} / \mathrm{ml}$ RNase A at $37^{\circ} \mathrm{C}$ for $30 \mathrm{~min}$, and washed through descending concentrations of SSC to $0.1 \times$ SSC at $60-70^{\circ} \mathrm{C}$. The slides then were dehydrated in ethanol, dried, and exposed to x-ray film (Kodak X-OMAT, Rochester, NY) for 3-5 d. Slides then were dipped in emulsion (Kodak NTB-2), exposed for several weeks, and developed, and the tissue sections were stained with $0.5 \%$ cresyl violet.

Quantitation of mRNA using Northern blots. Total RNA was extracted from various regions of mouse brain using RNA/DNA/protein isolation TRI Reagent (Molecular Research Center, Cincinnati, OH). Briefly, dissected tissue regions were homogenized in TRI reagent solution, suspended in a $1: 5$ volume of chloroform, and centrifuged at $12,000 \times \mathrm{g}$ for $15 \mathrm{~min}$. The RNA contained in the aqueous phase was transferred to new tubes and precipitated with isopropanol. The samples then were centrifuged at $12,000 \times g$ for 15 min to pellet the RNA. After washing the pellet with $75 \%$ cold ethanol, the pellet was dissolved in RNase-free water. The total RNA $(20-30 \mu \mathrm{g})$ was separated by standard methods on a formaldehyde-denaturing agarose gel. The RNA was blotted to $0.2 \mu \mathrm{m}$ neutral nylon membranes (Max-Strength Nytran, Schleicher \& Schuell, Keene, NH) and hybridized to ${ }^{32} \mathrm{P}$-labeled BDNF cRNA antisense probe $\left(\sim 3 \times 10^{6} \mathrm{cpm} / \mathrm{ml}\right)$. The membrane then was washed in graded SSC, dried, and exposed to PhosphorImager plates (Molecular Dynamics, Eugene, $O R$ ) and/or $x$-ray film. Relative abundance of $m R N A$ was quantified by reading the plates. For accurate quantification, the same blot was stripped off and hybridized to ${ }^{32} \mathrm{P}$-labeled $\beta$-actin probe. The ratio of $\mathrm{BDNF} / \beta$-actin densities then was used for comparison between the mutant and wild-type groups.

\section{RESULTS}

\section{Ataxia and impaired motor coordination in stg homozygotes}

Ataxic gait is one of the most noticeable neurological deficits in stg mice. On a flat surface, the ataxia is mild in the hindlimbs without obvious forelimb involvement and the righting response is normal. To analyze the motor deficit further, we performed quantitative tests of $s t g$ motor performance using the balance rod. In these tests, adult stg showed severe impairment of motor coordination and balance (Fig. 1). All wild-type control mice stayed on the stationary rod for $>60 \mathrm{sec}$ and, after three learning trials, main- 
tained good balance on the rotating rod for $>1 \mathrm{~min}$, the cutoff time of the experiment. In contrast, adult stg mice were unable to remain on the stationary rod for $>5 \mathrm{sec}$ (mean motor score, 3.2 $\mathrm{sec}$ ) and fell off the rod immediately when initiating movement or when the rod was rotated slowly.

Abnormal motor control in the mutant mice also is particularly evident while swimming in a waterbath, where they show severely disturbed righting responses with wild underwater tumbling motions. Placed in water, all stg/stg mutants ranging in age from 2 weeks postnatal to adult ( $\sim 100$ tested) required rescue to prevent drowning. In contrast, wild-type and heterozygous mice swam easily for $>1 \mathrm{~min}$, the cutoff time of the test. The swimming test proved to be a sensitive phenotypic screening test for affected mice from age P14 onward. Younger mice were not suitable for testing because they could float easily on the surface of the water.

\section{Cerebellar morphology in stg homozygotes}

To assess possible anatomical correlations of the behavioral defect, we measured cerebellar weight in 2-month-old stg mice and normal controls. The cerebella in $\mathrm{stg} / \mathrm{stg}$ mice are mildly hypoplastic, as evidenced by a significant $14 \%$ reduction in gross cerebellar wet weight $(+/+, 57.39 \pm 2.54 ; \mathrm{stg} / \mathrm{stg}, 49.34 \pm 3.85 ; p<0.01 ; n=$ 6). Light microscopic examination of $\mathrm{H}$-E-stained paraffin sections from $\mathrm{stg} / \mathrm{stg}$ mice revealed that despite the mild decrease in size, the overall pattern of cerebellar foliation appeared normal in stg mice (Fig. $2 A$ ). No major cytoarchitectural abnormalities were apparent in the stg/stg cerebellum. All neuron types had migrated successfully to their proper positions, and cross-sections through the stg cerebellum revealed the well defined laminar cortical structure found in normal cerebellum with a single layer of Purkinje cells aligned between the molecular and granule cell layers (Fig. 2B). The reduced weight of the stg cerebellum corresponded to a smaller size, suggesting generalized reduction in all anatomical elements. No gross changes in the thickness of the cerebellar cortex, the density of granule neurons, the size of the underlying white matter, or the appearance of the deep nuclei of stg cerebellum were observed in $\mathrm{H}$-E-stained sections.

\section{Early failure of BDNF mRNA expression in the stg mutant cerebellum}

Using a rat BDNF cDNA clone that is $98 \%$ homologous to the respective mouse sequence (Hófer et al., 1990), we localized BDNF mRNA by in situ hybridization in $+/+$ and $s t g / s t g$ mice. The expression pattern detected with this probe in adult $+/+$ mouse brain was essentially the same as that reported previously (Hofer et al., 1990; Phillips et al., 1990). The highest levels of BDNF mRNA were found in the cerebral cortex, hippocampal pyramidal and granule neurons, and in the cerebellar granule cells (left brain sections in Fig. $3 A, B$ ). In frontal brain regions, the cellular localization and levels of BDNF mRNA of the adult stg mutant were indistinguishable from those in wild-type control mice at both apical (Fig. $3 A$ ) and basal (Fig. $3 B$ ) horizontal levels. However, in marked contrast to the control brains, virtually no BDNF mRNA signal was detected in the cerebellar folia of $s t g / s t g$ mutant mice (right brain section in Fig. $3 A, B$ ), despite their normal histological appearance relative to the wild-type (Fig. $3 C, D$ ). In wild-type mouse cerebellum, the highest expression of BDNF mRNA was observed throughout the granule cell layer (Fig. $3 E$ ). In corresponding dark-field microscopy of emulsion-coated slides of $s \mathrm{tg} / \mathrm{stg}$ cerebellum, only background levels of label were observed (Fig. $3 F$ ), and the density of silver grains over the granule cell layer was no higher than in unlabeled areas of the slide
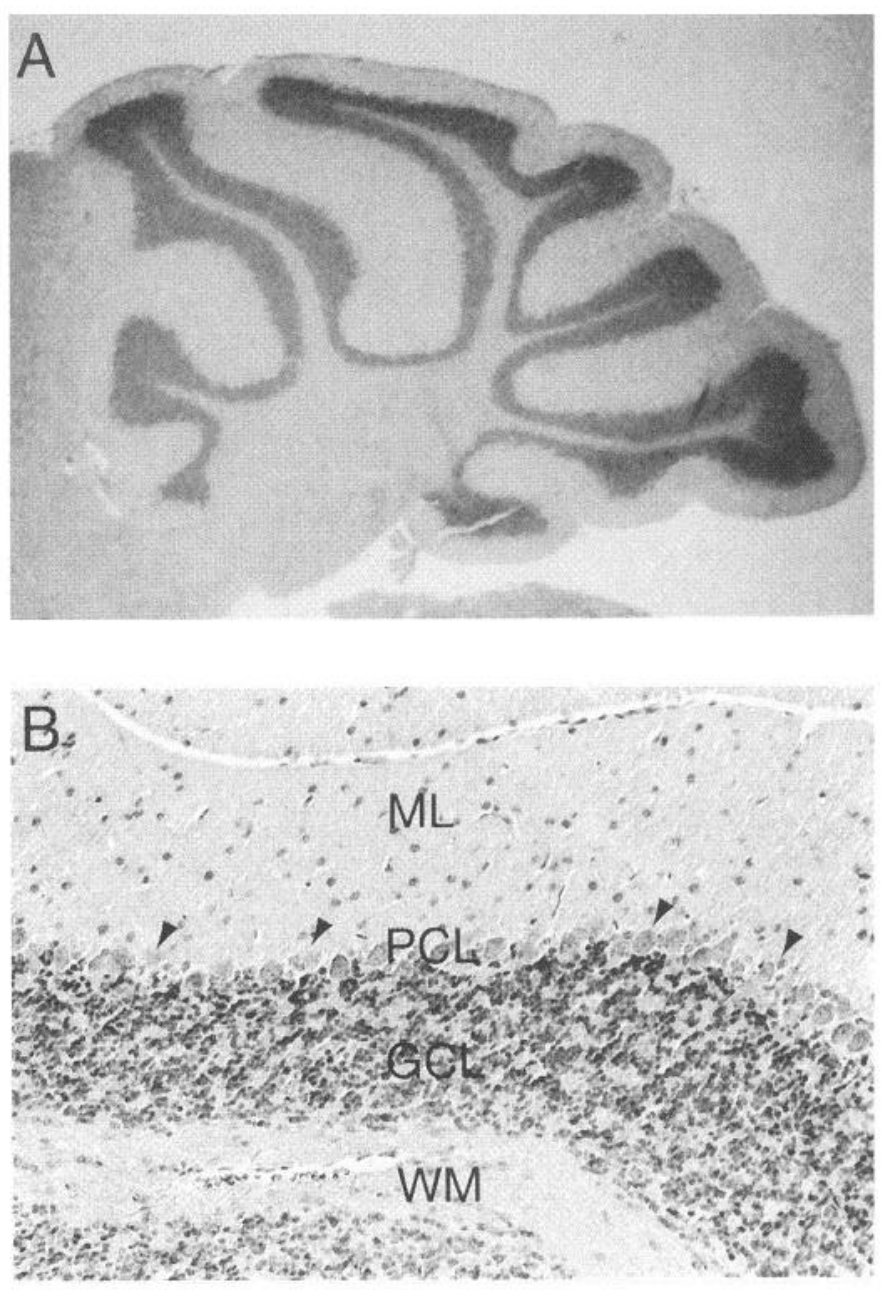

Figure 2. Light micrographs of H-E-stained paraffin sections of the cerebellum from adult stg mouse. $A$, Despite the mild decrease in cerebellar size, the sagittal section across the midline indicated normal pattern of foliation in stg cerebellum. Magnification $11 \times . B$, Higher magnification $(65 \times)$ shows a normal single layer of Purkinje cells $(P C L)$ aligned between the molecular layer $(M L)$ and granule cell layer $(G C L)$. Neither the thickness of the cerebellar cortex or underlying white matter $(W M)$ nor the density of granular neurons appeared to be altered in stg/stg cerebellum compared with wild-type control mice.

adjacent to the tissue sections. Analysis of a full series of coronal and sagittal sections revealed that BDNF mRNA signal was absent throughout the entire cerebellar cortex (data not shown). In contrast, BDNF mRNA hybridization levels in stg cerebellar deep nuclei, inferior olivary nuclei, and vestibular nuclei were not significantly different from wild-type sections (data not shown).

\section{Granule cell BDNF defect not found in $+/ s t g$ and tg/tg cerebellum}

To determine whether the profound cerebellar BDNF mRNA deficit was linked specifically to the stg mutation or to a nonspecific feature of impaired cerebellar function, we investigated BDNF mRNA levels in $+/$ stg heterozygous mice and in a second ataxic mutant with spike-wave seizures, the tottering (tg; chromosome 8) mutant. Adult $\mathrm{tg} / \mathrm{tg}$ mutants display a similar but lateronset (4-6 weeks) ataxic gait with mild cerebellar hypoplasia, but they swim normally and do not exhibit head-tossing behavior (Sidman et al., 1965; Noebels and Sidman, 1979). We found that the BDNF mRNA expression in the adult +/stg mouse was iden- 

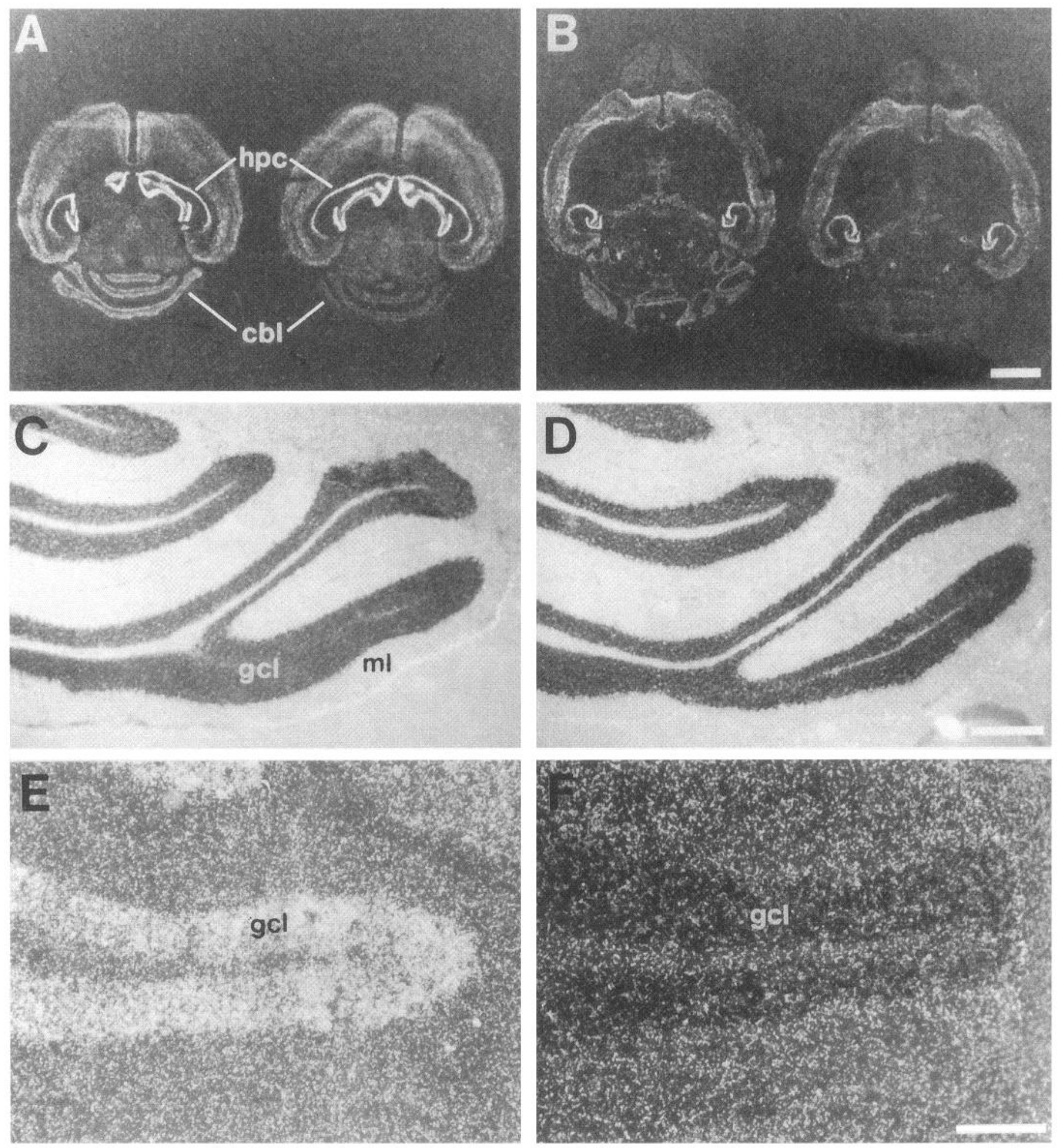

Figure 3. The expression pattern of BDNF mRNA in adult $+/+$ control and stg/stg mutant mice. $A, B$, Autoradiograms of horizontal brain sections at two different brain levels from $+/+($ left $)$ and $s t g / s t g$ (right). The highest levels of BDNF mRNA in the control mouse were found in the neocortex, hippocampus $(h p c)$, and cerebellum $(c b l)$. The pattern and the levels of BDNF mRNA expression in frontal brain regions of adult stg mutants were similar to those in control mice. However, in marked contrast to controls, there was a near total reduction in BDNF mRNA in the cerebellar cortex of stg/stg mutant mice. Low hybridization density in stg/stg sections rendered cerebellar structure barely visible. $C, D$, Light-field photomicrographs of cresyl violet-stained cerebellar cortex from control $(C)$ and stg $(D)$ brain. Note the comparable appearance of the densely stained granule cell layer $(g c l)$ in both genotypes; $\mathrm{ml}$, molecular layer. $E, F$, Dark-field photomicrographs of emulsion-dipped autoradiograms showing a single cerebellar folium. The granule cell layer $(\mathrm{gcl})$ in wild-type mice $(E)$ appeared as a densely labeled band of silver grains, whereas no specific labeling was found within the same layer in stg/stg $(F)$. The density of silver grains over the granule cell layer in stg cerebellum was no higher than the emulsion background level with no underlying tissue section. Scale bars: $A, B, 2 \mathrm{~mm} ; C, D, 1 \mathrm{~mm} ; E, F, 0.5 \mathrm{~mm}$. 

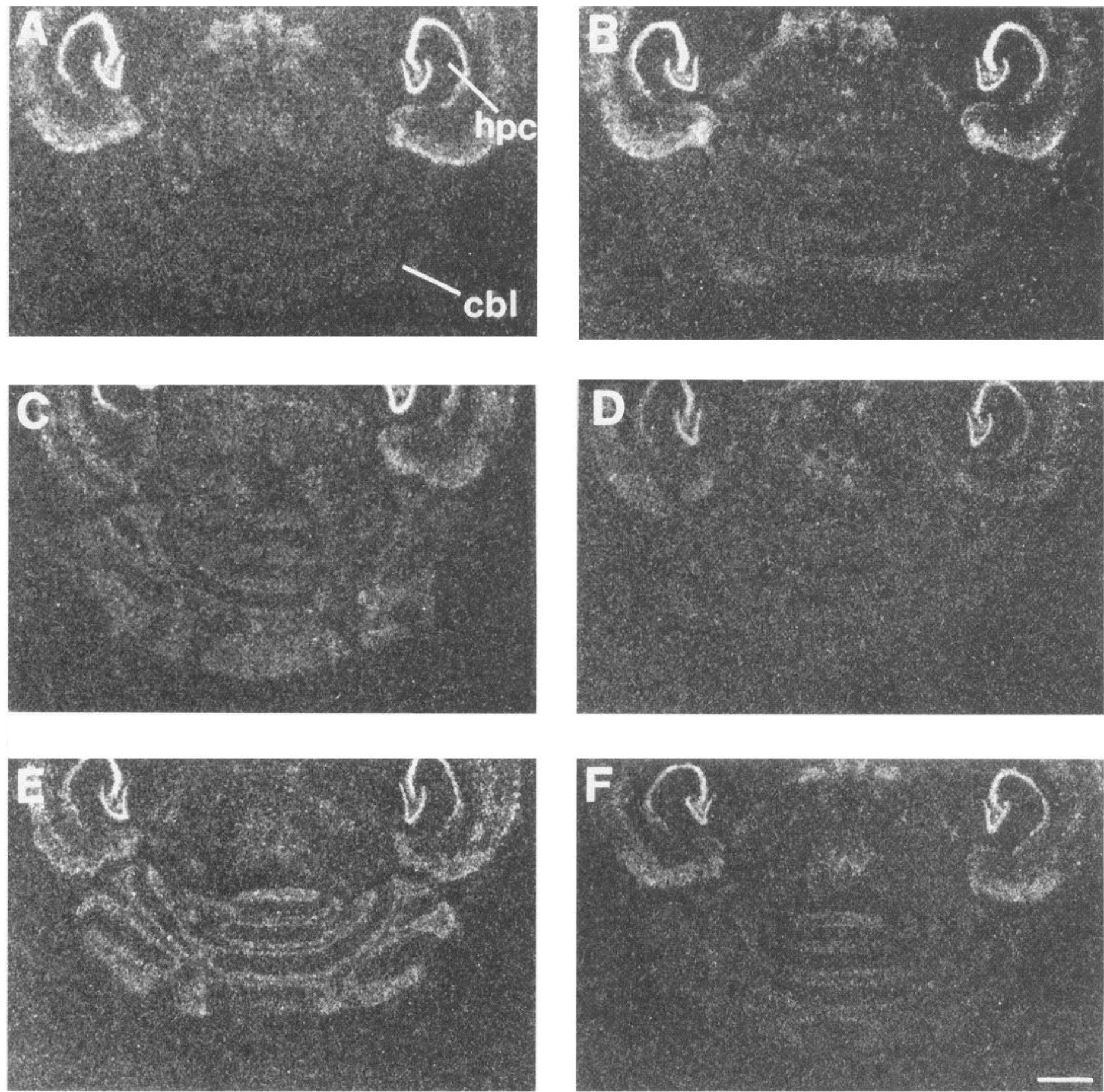

Figure 4. Developmental pattern of BDNF mRNA expression in $+/+$ and $s t g / s t g$ brain. $A, C, E$, BDNF mRNA expression steadily increased in the $+/+$ cerebellum $(c b l)$ from age $\mathrm{P} 15(A)$ through $\mathrm{P} 20(C)$ and $\mathrm{P} 30(E)$, whereas the levels in frontal brain regions, including neocortex and hippocampus $(h p c)$, were already high at the earliest age tested (compare $h p c$ in $A$ and $E$ ). $B, D, F$, In stg/stg brain, the absence of cerebellar BDNF mRNA signal was observed throughout postnatal development at P15 $(B), \mathrm{P} 20(D)$, and $\mathrm{P} 30(F)$. Scale bar, $1 \mathrm{~mm}$.

tical to $+/+$ controls, indicating a lack of gene dosage effect for BDNF mRNA expression (data not shown). The adult $t g / t g$ brain also expressed normal levels of BDNF mRNA throughout the forebrain and cerebellum (data not shown), suggesting that the granule cell BDNF deficit in $s t g / s t g$ mice is not related to either the secondary effects of spike-wave seizures, which do not involve the cerebellar cortex, or to a secondary reactive neurotrophic response to cerebellar hypoplasia.
The final stages of cerebellar development in mice and other rodents, particularly with respect to the migration and terminal differentiation phase of granule cells, occur during the first 3 postnatal weeks (Miale and Sidman, 1961; Fujita et al., 1966; Altman, 1972). To examine the developmental regulation of BDNF mRNA in stg/stg cerebellum, we compared in situ hybridization patterns in stg/stg and $+/+$ mice at ages P15, P20, and P30. As shown in Figure 4, $A, C$, and $E$, the level of BDNF expression 
A

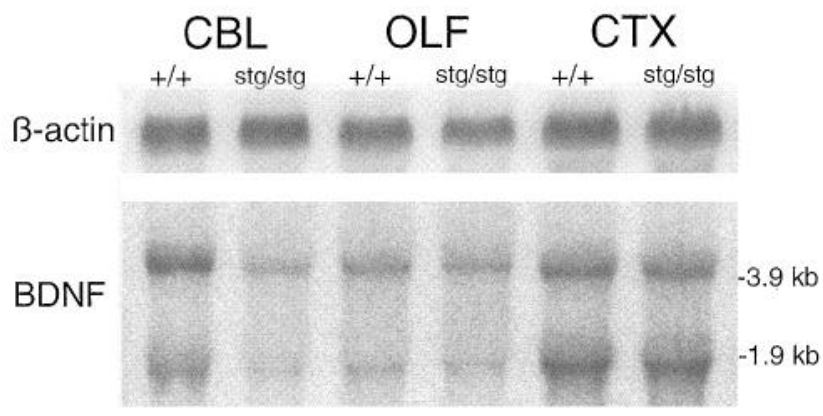

B

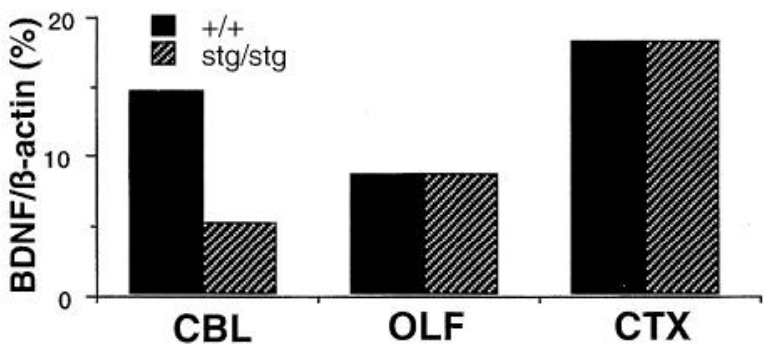

Figure 5. Northern blot analysis of BDNF mRNA in adult $+/+$ and stg/stg brain regions. Thirty micrograms of total RNA from cerebellum $(C B L)$ and neocortex $(C T X)$ and $20 \mu \mathrm{g}$ from olfactory bulb $(O L F)$ were loaded on a gel and then hybridized with ${ }^{32} \mathrm{P}$-labeled BDNF cRNA and $\beta$-actin probes by Northern blotting. $A$, BDNF mRNAs appeared as two bands migrating at $\sim 1.6$ and $4.0 \mathrm{~kb}$. The blots revealed a striking reduction in both forms of BDNF mRNA molecules in the $s t g / s t g$ cerebellum, but not in neocortex or olfactory bulbs. $B$, Densitometric comparison of the ratio of BDNF mRNA $/ \beta$-actin mRNA signals showed a $70 \%$ reduction in BDNF mRNA in stg cerebellum with no significant changes in the neocortex or olfactory bulb regions.

in $+/+$ cerebellum increases during postnatal development later than in frontal brain regions, which is similar to the timetable reported in rats (Rocamora et al., 1993). In cerebellar granule cells, BDNF mRNA levels reached maximal levels between the third and fourth postnatal weeks and remained high in the adult (Figs. 3,4$)$. In contrast, a virtual absence of BDNF.mRNA in the stg/stg granule cell layer (Fig. $4 B, D, F$ ) was observed consistently at all postnatal ages examined, including P15, coincident with the onset of ataxia, as well as at later ages (P20 and P30).

Quantitative Northern blot analysis of total RNA hybridized with a BDNF cRNA probe confirmed the results obtained by in situ hybridization (Fig. 5). Northern blots revealed two characteristic bands, corresponding to the two forms of BDNF mRNA of 1.6 and $4.0 \mathrm{~kb}$ described earlier for rodent brain (Hofer et al., 1990; Maisonpierre et al., 1990). Of interest, the $4.0 \mathrm{~kb}$ form was expressed at higher levels than the $1.6 \mathrm{~kb}$ form in the cerebellum $(4.0 \mathrm{~kb} / 1.6 \mathrm{~kb}$ ratio, $1: 0.5)$, whereas in neocortex the ratio of the forms was reversed (1:1.5; Fig. 5A). Comparison of the bands between the two genotypes revealed a striking reduction in both forms of BDNF mRNA molecules in stg/stg cerebellum compared with $+/+$ control. BDNF mRNA levels for both transcripts were unchanged in the mutant neocortex and olfactory bulb (Fig. $5 A$ ).
Densitometric comparison of BDNF mRNA signals with those for a control protein, $\beta$-actin, obtained by reprobing the same blots, showed a 70\% reduction in both forms of BDNF mRNA in whole stg/stg cerebellar samples but no significant change in the frontal cortex or olfactory bulb samples (Fig. $5 B$ ).

\section{Lack of associated changes in trkB mRNA expression}

To determine whether the striking lack of cerebellar BDNF mRNA and, presumably, BDNF protein had any influence on the expression level of BDNF receptors, adjacent sections of adult $+/+$ and $s t g / s t g$ mouse brain were hybridized to various trk $\mathrm{B}$ receptor probes. Two different forms of the BDNF receptor TrkB have been described (Klein et al., 1990; Middlemas et al., 1991). Full-length TrkB is characterized by an extracellular ligand-binding domain, a transmembrane domain, and an intracellular domain containing a tyrosine kinase motif involved in signal transduction (Barbacid, 1994). Truncated trkB encodes an identical extracellular ligand-binding domain but lacks the intracellular tyrosine kinase, and its role in signal transduction presently is unknown. We used three different probes in the in situ hybridization experiments, binding nondifferentially to both receptor forms or selectively to the full-length or to the truncated receptor only (pan, $t r k \mathrm{~B}^{+}$, and $t r k \mathrm{~B}^{-}$probes). No detectable differences were found in the expression patterns of mRNAs coding for any of the receptor isoforms between cerebellum of $\mathrm{stg} / \mathrm{stg}$ mice when compared to wild-type controls (Fig. 6).

\section{NGF and NT-3 mRNA levels are unaltered by stg gene action}

To assess further the selectivity of the stg mutant gene action on cerebellar BDNF mRNA levels, we performed in situ hybridization for the two related neurotrophins NGF and NT-3 that also expressed in the developing cerebellum (Maisonpierre et al., 1990; Rocamora et al., 1993). The mRNAs for both neurotrophins, NGF and NT-3, are expressed at much lower levels than BDNF mRNA in the adult mouse (Rocamora et al., 1993). In stg/stg cerebellum, both NGF and NT-3 were expressed at age P20 (Fig. 7) at levels indistinguishable from control brains (data not shown). We also found no significant genotypic difference in their expression in the adult cerebellum or in other brain areas (data not shown).

\section{DISCUSSION}

This report establishes a specific and pronounced deficit in BDNF mRNA expression in the cerebellum of the stg mouse. Other brain areas of this spontaneous mutant with ataxia and frequent generalized spike-wave seizures express normal levels of BDNF. mRNAs for other neurotrophins, including NGF and NT-3 throughout the brain of $s t g$, as well as for the functional full-length and the truncated BDNF receptors trkB were present at normal levels. Northern blot analysis of total RNA showed a 70\% reduction in BDNF mRNA levels in the cerebellum of adult stg mice. Very pronounced reduction in cerebellar BDNF mRNA also was observed at various postnatal ages, including P15, the onset of ataxia, and at later developmental stages (P20 and P30). We also have characterized further the behavioral deficits of the stg mouse. We found that, aside from the characteristic ataxic gait and head-tossing movement of this mutant, its motor coordination and balance are severely impaired. These behavioral deficits and the failure of BDNF mRNA expression in the cerebellum are associated with a slight reduction in cerebellar weight.

\section{Regional control of BDNF expression}

Our finding a selective lack of BDNF mRNA expression in stg cerebellum provides a striking example of regional regulation of a 

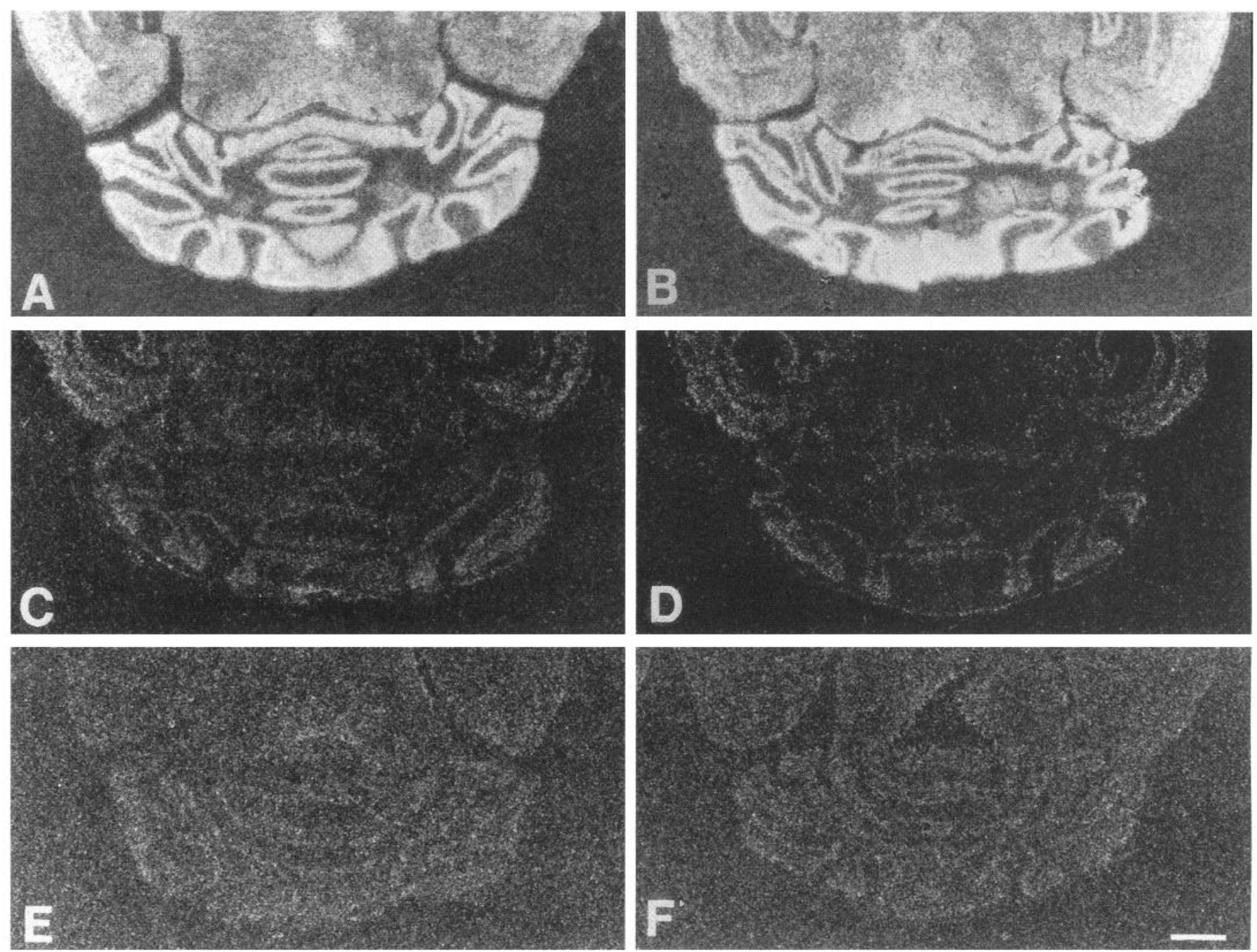

Figure 6. Cerebellar $t r k \mathrm{~B}$ mRNA expression in adult $+/+$ control and $s t g / s t g$ mutant mice. In situ hybridization autoradiograms with three different probes hybridizing to all known $\operatorname{trk\mathrm {B}}$ transcripts in $+/+(A, C, E)$ and $\operatorname{stg} / \operatorname{stg}(B, D, F)$ brain. $A, B, \operatorname{Trk\mathrm {B}}$ pan probe; $C, D, t r k \mathrm{~B}^{+}$probe selective for the full-length form; $E, F, T r k \mathrm{~B}^{-}$probe selective for the truncated form only. No significant difference was observed in the expression patterns of mRNAs coding for these trkB-receptor isoforms between the two genotypes. Scale bar, $1 \mathrm{~mm}$.

prominent neurotrophic factor in the central nervous system. Molecular cloning of the rat BDNF gene has revealed a complex gene structure comprising four short $5^{\prime}$ exons and one $3^{\prime}$ exon encoding the mature BDNF protein. A separate promoter is present upstream of each $5^{\prime}$ exon (Timmusk et al., 1993). Alternative activation of these promoters and differential splicing can result in synthesis of several distinct BDNF mRNAs with different 5 '-untranslated exons. In situ hybridization with exon-specific antisense cRNA probes reveals distinct and overlapping expression patterns in different frontal brain regions (Timmusk et al., 1993). Distinct patterns of regulation mediated by the various promoters also were observed after kainic acid-induced changes in neuronal activation (Metsis et al., 1993; Kokaia et al., 1994). Such a mechanism may provide the basis for the differences in upregulated BDNF mRNA expression observed after excessive neuronal stimulation in various experimental models (Gall and Isackson, 1989; Zafra et al., 1990; Ballarin, 1991; Ernfors et al., 1991; DugichDjordjevic et al., 1992; Lindvall et al., 1992). Among the five upstream exons of the BDNF gene, the third exon was reported recently to be expressed higher than other exons in the rat cerebellum by quantitative PCR analysis (Bishop et al., 1994). However, no information is available yet regarding which promoter(s) may be responsible for cerebellum-specific BDNF expression in the mouse. Our data strongly suggest the existence of a regional element, either a promoter or a transcription factor, that specifically regulates the BDNF gene in cerebellar granule cells.

\section{The stg locus selectively suppresses BDNF expression in cerebellar granule cells}

The stg mutant gene product has not yet been defined, but is likely to interfere with the level or binding of a factor that activates BDNF gene transcription at this cerebellum-specific regulatory site. The BDNF gene has been mapped to chromosome 2 in the mouse (Ozcelik et al., 1991), excluding the gene itself as a candidate for the stg locus on chromosome 15 (Noebels et al., 1990). Normal BDNF expression in the remainder of the stg brain also suggests that regulation by other transactivating factors remains functionally intact. The lack of a gene dosage-related reduction in cerebellar BDNF mRNA expression in the stg heterozygote excludes a dominant negative mutation involving the cerebellar transcription factor, but 

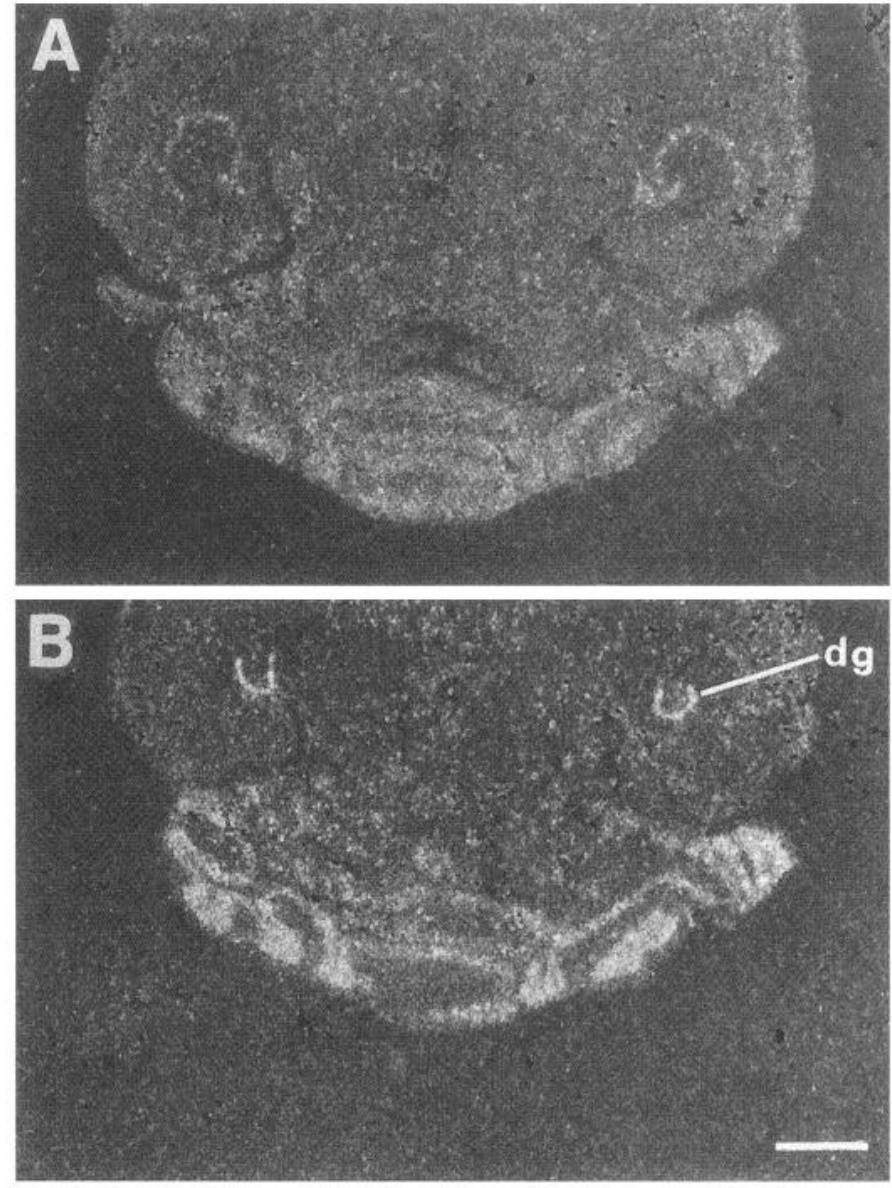

Figure 7. Expression pattern of NGF and NT-3 mRNAs in $s t g / s t g$ mouse cerebellum at age P20. The mRNAs for NGF $(A)$ and NT-3 $(B)$ were expressed at normal levels in $s t g / s t g$ mice. Expression levels in adult mice were both lower (but equal to each other) than at P20 in $+/+$ and stg/stg cerebellum (data not shown); $d g$, dentate gyrus of the hippocampus. Scale bar, $1 \mathrm{~mm}$.

allows for the possibility that the mutant gene encodes a factor required only in single-copy transcript levels. The normal appearance of cerebellar BDNF mRNA in the related $t g$ mutant is significant for two reasons. First, it demonstrates that the reduction is not a nonspecific result of cerebellar pathophysiology, because both mutants show a prominent ataxic phenotype. Second, it indicates that the frequent neocortical spike-wave seizures seen in both mutants (Noebels and Sidman, 1979; Qiao and Noebels, 1991) are not producing an activity-dependent suppression of granule cell BDNF transcription. Although electroencephalograph seizures cannot be recorded from the cerebellar cortex in either mutant, a similar generalized discharge pattern has been shown to alter the firing patterns of Purkinje cells (Kandel and Buzáki, 1993), presumably by activating descending corticocerebellar pathways. Finally, there is no independent evidence for any activity-dependent alterations in various markers for cell injury in the stg/stg cerebellum, including the immediate-early genes c-fos, c-jun, and Zif268 (Nahm and Noebels, 1994) and the stress proteins hsp 72 (heat shock protein-72), GFAP (glial fibrillary acidic protein), and NADPH (reduced nicotinamideadenosine dinucleotide phosphate)-diaphorase (Chafetz et al., 1995). These data suggest that the site of stg gene action in the cerebellum is linked closely to BDNF gene transcription. It could be a signal factor that only presents in the cerebellum or only expresses postnatally, at a time when brain regions other than the late-developing cerebellum already might have passed a hypothetical critical period sensitive to the primary effect of the stg mutation.

\section{Potential role of granule cell BDNF failure in the stg ataxic phenotype}

Our report establishes a specific and pronounced deficit in BDNF, but not NGF or NT-3, mRNA expression in the cerebellar cortex of the stg mouse. mRNAs for the functional full-length and the truncated TrkB receptors also were expressed at normal levels, demonstrating that, unlike NGF and its cognate receptor TrkA (Holtzman et al., 1992; Venero et al., 1994), the expression of TrkB does not depend critically on BDNF.

In the cerebellum, postulated functions of BDNF are based primarily on in vitro studies. BDNF enhances survival of the granule cells in embryonic cerebellar cultures (Segal et al., 1992), induces sprouting, and protects them against glutamate-induced neurotoxicity (Lindholm et al., 1993). BDNF also induces the paired boxcontaining gene family $\operatorname{Pax}(2,3$, and 6$)$ in cerebellar primary cultures (Kioussi and Gruss, 1994). Our findings in stg/stg cerebellum suggest that a near total lack of BDNF has little influence on the major program of neuronal proliferation and migration during cerebellar development. Rather, BDNF may act at later stages of cerebellar granule cell maturation. These results agree with the data reported by Gao et al. (1995) from in vitro weaver mutant cerebellar cultures, showing that BDNF and NT-4/5 promote neurite extension and survival of differentiated cerebellar granule cells but do not stimulate proliferation of granule cell precursors. A similar role of BDNF in maturation of sensory epithelia cells has been postulated recently in BDNF - - mutants (Ernfors et al., 1995). Our results do not support the proposal generated from embryonic culture studies that BDNF promotes the initial commitment in immature granule neurons, whereas NT-3 directs the subsequent maturation in more mature granule cells (Segal et al., 1992).

Although the inherited ataxia phenotype may depend ultimately on a series of still unknown pleiotropic effects of the stg locus, three lines of evidence suggest that the early absence of BDNF is involved directly. First, the onset of behavioral ataxia (at P15) in stg/stg mice occurs at a point in cerebellar development at which the BDNF gene normally is activated. This time point corresponds to the later stages of granule cell division and differentiation. Granule cell proliferation normally continues until approximately P20 (Fujita et al., 1966), and migration, neurite outgrowth, and the formation of synapses within mossy-fiber glomeruli continue for $>30 \mathrm{~d}$ postnatally (Altman, 1972). Second, targeted deletion of the BDNF gene in the mouse reproduces essential elements of the stg behavioral and neuropathological ataxia phenotype. Despite a global loss of the neurotrophin in the BDNF $-/-$ mutant leading to severe cell loss in sensory ganglia, the cerebellar architecture is spared, as it is in stg/stg mice, and no cytological lesions are evident, at least until the $-/-$ animals die in the third postnatal week. Third, BDNF has been proposed to play a direct role in synaptogenesis and adaptive changes in connectivity (Gall, 1992). Recently, excess BDNF has been shown to inhibit ocular dominance column formation in the visual cortex and, therefore, may influence the activity-dependent control of axonal branching during development (Cabelli et al., 1995). Absence of BDNF in the developing stg cerebellar cortex, therefore, could contribute to a dystrophic neuropil and underlie the relative cerebellar hypoplasia and ataxia in the stg/stg mouse.

\section{REFERENCES}

Altman J (1972) Postnatal development of the cerebellar cortex in the rat. III. Maturation of the components of the granular layer. J Comp Neurol 145:465-514. 
Ballarin M, Ernfors P, Lindefors N, Persson H (1991) Hippocampal damage and kainic acid injection induce a rapid increase in mRNA for BDNF and NGF in the rat brain. Exp Neurol 114:35-43.

Barbacid M (1994) The Trk family of neurotrophin receptors. J Neurobiol 25:1386-1403.

Bishop JF, Mueller GP, Mouradian MM (1994) Alternate 5' exons in the rat brain-derived neurotrophic factor gene: differential patterns of expression across brain regions. Mol Brain Res 26:225-232.

Cabelli RJ, Hohn A, Shatz CJ (1995) Inhibition of ocular dominance column formation by infusion of NT-4/5 or BDNF. Science 267:1662-1666.

Chafetz RS, Nahm WK, Noebels JL (1995) Aberrant expression of neuropeptide $\mathrm{Y}$ in hippocampal mossy fibers in the absence of local cell injury following the onset of spike-wave synchronization. Mol Brain Res 31:111-121.

Conover JC, Erickson JT, Katz DM, Bianchi LM, Poueymirou WT, McClain J, Pan L, Helgren M, Ip NY, Boland P, Friedman B, Weigand S, Vejsada R, Kato AC, DeChiara TM, Yancopoulos GD (1995) Neuronal deficits, not involving motor neurons, in mice lacking BDNF and/or NT4. Nature 375:235-238.

Dugich-Djordjevic MM, Tocco G, Willoughby DA, Najm I, Pasinetti G, Thompson RF, Baudry M, Lapchak PA, Hefti F (1992) BDNF mRNA expression in the developing rat brain following kainic acid-induced seizure activity. Neuron 8:1127-1138.

Ernfors P, Bengzon J, Kokaia Z, Persson H, Lindvall O (1991) Increased levels of messenger RNAs for neurotrophic factors in the brain during kindling epileptogenesis. Neuron 7:165-176.

Ernfors P, Lee KF, Jaenisch R (1994) Mice lacking brain-derived neurotrophic factor develop with sensory deficits. Nature 368:147-150.

Ernfors P, Van De Water T, Loring J, Jaenisch R (1995) Complementary roles of BDNF and NT-3 in vestibular and auditory development. Neuron 14:1153-1164.

Fujita S, Shimada M, Nakamura T (1966) ${ }^{3} \mathrm{H}$-Thymidine autoradiographic studies on the cell proliferation and differentiation in the cxtcrnal and internal granular layers of the mouse cerebellun. J Comp Neurol 128:191-208.

Gall CM (1992) Regulation of brain neurotrophin expression by physiological activity. Trends Pharmacol Sci 13:401-403.

Gall CM, Isackson PJ (1989) Limbic seizures increase neuronal production of messenger RNA for nerve growth factor. Science 245:758-761.

Gao WQ, Zheng JL, Karihaloo M (1995) Neurotrophin-4/5 (NT-4/5) and brain-derived neurotrophic factor (BDNF) act at later stages of cerebellar granule cell differentiation. J Neurosei 15:2656-2667.

Hofer M, Pagliusi SR, Hohn A, Leibrock J, Barde YA (1990) Regional distribution of brain-derived neurotrophic factor $\mathrm{mRNA}$ in the adult mouse brain. EMBO J 9:2459-2464.

Holtzman DM, Li Y, Parada LF, Kinsman S, Chen CK, Valletta JS, Zhou J, Long JB, Mobley WC (1992) p140Trk mRNA marks NGFrcsponsive forcbrain neurons: evidence that trk gene expression is induced by NGF. Neuron 9:465-478.

Ingram DK, London ED, Reynolds MA, Waller SB, Goodrick CL (1981) Differential effects of age on motor performance in two mouse strains. Neurobiol Aging 2:221-227.

Jones KR, Farinas I, Backus C, Reichardt LF (1994) Targeted disruption of the BDNF gene perturbs brain and sensory neuron development but not motor neuron development. Cell 76:989-999.

Kandel A, Buzsáki G (1993) Cerebellar neuronal activity correlates with spike and wave EEG patterns in the rat. Epilepsy Res 16:1-9.

Kioussi C, Gruss P (1994) Differential induction of Pax genes by NGF and BDNF in cerebellar primary cultures. J Cell Biol 125:417-425.

Klein R, Conway D, Parada LF, Barbacid M (1990) The $t r k$ B tyrosine protein kinase gene codes for a second neurogenic receptor that lacks the catalytic kinase domain. Cell 61:647-656.

Klein R, Parada LF, Coulier F, Barbacid M (1989) TrkB, a novel tyrosine protein kinase receptor expressed during mouse neural development. EMBO J 8:3701-3709.

Kokaia Z, Metsis M, Kokaia M, Bengzon J, Elmer E, Smith ML, Timmusk T, Siesjo BK, Persson H, Lindvall O (1994) Brain insults in rats induce increased expression of the BDNF gene through differential use of multiple promoters. Eur J Neurosci 6:587-596.

Leibrock J, Lottspeich F, Hohn A, Hofer M, Hengerer B, Masiakowski P, Thoenen H, Barde YA (1989) Molecular cloning and expression of brain-derived neurotrophic factor. Nature 341:149-152.
Lindholm D, Dechant G, Heisenherg CP, Thenen H (1993) Brainderived neurotrophic factor is a survival factor for cultured rat cerebellar granule neurons and protects them against glutamate-induced neurotoxicity. Eur J Ncurosci 5:1455-1464.

Lindvall O, Ernfors P, Bengzon J, Kokaia Z, Smith ML, Siesjo BK, Persson H (1992) Differential regulation of mRNAs for nerve growth factor, brain-derived neurotrophic factor, and neurotrophin 3 in the adult rat brain following cerebral ischemia and hypoglycemic coma. Proc Natl Acad Sci USA 89:648-652.

Liu X, Ernfors P, Wu H, Jaenisch R (1995) Sensory but not motor neuron deficits in mice lacking NT4 and BDNF. Nature 375:238-241.

Maisonpierre PC, Belluscio L, Friedman B, Alderson RF, Wiegand SJ, Furth ME, Lindsay RM, Yancopoulos GD (1990) NT-3, BDNF, and NGF in the developing rat nervous system: parallel as well as reciprocal palterns of expression. Neuron 5:501-509.

McNeill TH, Koek LL, Brown SA, Rafols JA (1990) Quantitative analysis of age-related dendritic changes in medium spiny I (MSI) striatal neurons of C57BL/6N mice. Neurobiol Aging 11:537-550.

Metsis M, Timmusk T, Arenas E, Persson H (1993) Differential usage of multiple brain-derived neurotrophic factor promoters in the rat brain following neuronal activation. Proc Natl Acad Sci USA 90:8802-8806.

Miale IL, Sidman RL (1961) An autoradiographic analysis of histogenesis in the mouse cerebellum. Exp Neurol 4:277-296.

Middlemas DS, Lindberg RA, Hunter T (1991) TrkB, a neural receptor protein-tyrosine kinase: evidence for a full-length and two truncated receptors. Mol Cell Biol 11:143-153.

Nahm WK, Noebels JL (1994) The molecular mechanisms mediating mossy fiber synaptic reorganization differ between spike-wave and convulsive epilepsy (Abstr). Epilepsia 35:84A.

Noebels JL, Sidman RL (1979) Inherited epilepsy: spike-wave and focal motor seizures in the mutant mouse tottering. Science 204:1334-1336.

Noebels JL, Qiao X, Bronson RT, Spencer C, Davisson MT (1990) Stargazer: a new neurological mutant on chromosome 15 in the mouse with prolonged cortical seizures [published erratum appears in Epilepsy Res (1992) 5:72]. Epilepsy Res 7:129-135.

Ozcelik T, Rosenthal A, Francke U (1991) Chromosomal mapping of brain-derived neurotrophic factor and neurotrophin-3 genes in man and mouse. Genomics 10:569-575.

Phillips HS, Hains JM, Laramee GR, Rosenthal A, Winslow JW (1990) Widespread expression of BDNF but not NT3 by target areas of basal forebrain cholinergic neurons. Science 250:290-294.

Qiao X, Noebels JL (1991) Genetic and phenotypic heterogeneity of inherited spike-wave epilepsy: two mutant gene loci with independent cerebral excitability defects. Brain Res 555:43-50.

Qiao X, Noebels JL (1993) Developmental analysis of hippocampal mossy fiber outgrowth in a mutant mouse with inherited spike-wave seizures. J Neurosci 13:4622-4635.

Rocamora N, Garcia Ladona FJ, Palacios JM, Mengod G (1993) Differential expression of brain-derived neurotrophic factor, neurotrophin-3, and low-affinity nerve growth factor receptor during the postnatal development of the rat cerebellar system. Brain Res 17:1-8.

Scott J, Selby M, Urdea M, Quiroga M, Bell GI, Rutter WJ (1983) Isolation and nucleotide sequenec of a cDNA encoding the precursor of mouse nerve growth factor. Nature 302:538-540.

Segal RA, Takahashi H, McKay RD (1992) Changes in neurotrophin responsiveness during the development of cerebellar granule neurons. Neuron 9:1041-1052.

Sidman RL, Green MC, Appel SH (1965) Catalog of the neurological mutants of the mouse. Cambridge: Harvard UP.

Timmusk T, Palm K, Metsis M, Reintam T, Paalme V, Saarma M, Persson H (1993) Multiple promoters direct tissue-specific expression of the rat BDNF gene. Neuron 10:475-489.

Venero JL, Beck KD, Hefti F (1994) Intrastriatal infusion of nerve growth factor after quinolinic acid prevents reduction of cellular expression of choline acetyltransferase messenger RNA and trkA messenger RNA, but not glutamate decarboxylase messenger RNA. Neuroscience 61:257-268.

Zafra F, Hengerer B, Leibrock J, Thoenen H, Lindholm D (1990) Activity dependent regulation of BDNF and NGF mRNAs in the rat hippocampus is mediated by non-NMDA glutamate receptors. EMBO J 9:3545-3550. 